\title{
Effect of hypothermic perfusion on corneal endothelial morphology
}

\author{
MARK J. MANNIS, ROBERT B. MILLER, EDWARD C. CARLSON, \\ DAVE HINDS, AND DONALD R. MAY \\ From the Cornea Research Laboratory, Department of Ophthalmology, and the \\ Department of Human Anatomy, School of Medicine, University of California, Davis, USA
}

SUMMARY The effect of moderate in-vivo hypothermic perfusion on corneal endothelial integrity was studied in the cat. Eleven cats underwent in-vivo anterior chamber perfusion for 30 minutes with either normothermic $\left(23^{\circ} \mathrm{C}\right)$ or hypothermic $\left(5^{\circ} \mathrm{C}\right)$ perfusate. Corneas were then evaluated clinically (biomicroscopy), functionally (vital staining), and morphologically (scanning electron microscopy) for changes attributable to hypothermic perfusion. All 3 modes of evaluation suggested no difference in corneal endothelial integrity under the 2 experimental perfusion conditions. At the clinical and scanning electron microscope levels hypothermic perfusion does not show any effects on the corneal endothelium. Regional hypothermia is of theoretical and potential utility in procedures involving prolonged intraocular perfusion.

The developing technology of modern ophthalmic surgery includes many intraocular procedures during which the eye is perfused with large volumes of irrigating solution. Such intraocular perfusion is standard procedure in phacoemulsification, in various techniques of extracapsular cataract extraction, and in the burgeoning field of closed pars plana surgery for lensectomy and vitrectomy. Previous work on intraocular perfusion has concentrated on the effects of mechanical trauma from irrigation ${ }^{12}$ and the chemical composition of irrigating solutions on the viability of the corneal endothelium. ${ }^{3-6}$

Hypothermic conditions lower metabolic rates, thereby decreasing oxygen demand. This observation has been utilised experimentally and clinically by several surgical disciplines ${ }^{7}$ including cardiovascular surgery, ${ }^{89}$ urological surgery, ${ }^{1011}$ gastrointestinal surgery, ${ }^{12}$ and neurosurgery ${ }^{13}$ to mitigate the effects of anoxia. Recent work has extended this interest to the effects of intraoperative hypothermic perfusion on retinovascular tissue. ${ }^{14}$ In relation to the cornea the functional and ultrastructural changes from controlled freezing have been extensively studied, ${ }^{15-17}$ and cryopreservation has become a significant adjunct to the banking of corneal tissue. ${ }^{18}$ As early as 1955 the phenomenon of temperature reversal

Correspondence to Mark J. Mannis, MD, Department of Ophthalmology, 4301 X Street, Room 251, Sacramento, California 95817, USA. (corneal hydration under hypothermic conditions) was demonstrated. ${ }^{19}$ There is less information, however, on the effects of more moderate hypothermia on the corneal endothelium in vivo, specifically as it relates to intraocular perfusion. The present study is concerned with the effects of moderate in-vivo hypothermic perfusion on corneal endothelial morphology.

\section{Material and methods}

Adult cat corneal endothelium was used owing to the similarity between feline and human endothelial regenerative capacity. ${ }^{20}$ Thirteen healthy adult cats $(2 \cdot 5-3.5 \mathrm{~kg}$ ) were studied. Five animals (group I) underwent hypothermic perfusion in one eye. The fellow eye in each animal served as an unmanipulated control. Six animals (group II) underwent normothermic perfusion in one eye with the opposite eye likewise serving as an unmanipulated control. Two cats served as double (bilateral) nonperfused controls.

Anaesthesia was obtained with an intramuscular injection of ketamine hydrochloride $(15-20 \mathrm{mg} / \mathrm{lb}=$ $6 \cdot 8-9 \cdot 1 \mathrm{mg} / \mathrm{kg})$ and acepromazine maleate $(0 \cdot 15-0 \cdot 2$ $\mathrm{mg} / \mathrm{lb}=0.07-0.09 \mathrm{mg} / \mathrm{kg}$ ). With a lid speculum in place, the nictitating membrane was retracted with a 4-0 silk suture. Two limbal corneal incisions were made with a no. 52S Beaver blade at the 10 and 2 o'clock limbal positions. Through the temporal 
incision a 20 gauge blunt infusion cannula was inserted into the anterior chamber, avoiding contact with iris and corneal endothelium. Through this cannula, Balanced Salt Solution (BSS, Alcon Laboratories Inc.) was infused by gravity feed through standard intravenous tubing. To achieve hypothermic perfusion temperatures the BSS was diverted through a coil of tubing immersed in a salt water ice bath. For normothermic perfusion the cooling coil was bypassed. Flow rate was maintained at $5 \pm 0.5 \mathrm{ml} / \mathrm{min}$ and was monitored continuously with a Gilmont no. 12 flowmeter.

A $2.5 \mathrm{~cm}$ blunt-tipped Bailey 23 gauge thermistor, Model MT-5 was placed through the remaining incision and was positioned centrally in the anterior chamber. Thermistor readings were registered on a Doric trendindicator $400 \mathrm{~A}$ with continuous digital display. The thermistor was calibrated with a United States National Bureau of Standards thermometer to within $0 \cdot 5^{\circ} \mathrm{C}$.

Since current operating room procedure is to perfuse at ambient temperatures, the normothermic perfusion was at room temperature $\left(23 \pm 2^{\circ} \mathrm{C}\right)$. Hypothermic perfusion was maintained at $5 \pm 1^{\circ} \mathrm{C}$. Anterior chamber temperature was monitored at 2 minute intervals. Total perfusion time was 30 minutes. The perfusate left the anterior chamber through both incisions.

After a total of 30 minutes of perfusion time both instruments were withdrawn, and each incision was closed with a single partial depth suture of 10-0 nylon. All animals were maintained for 24 hours and were then killed under anaesthesia with intracardiac potassium chloride. Immediately post mortem both the perfused and control eyes were evaluated grossly for corneal clarity. The eyes were then enucleated, and a corneal-scleral cap was carefully removed with corneal scissors and placed epithelial side down on a Teflon block. A central $8 \mathrm{~mm}$ corneal button was removed with a corneal trephine. Corneal buttons were prepared for electron microscopy by being bathed in $0.1 \mathrm{M}$ sodium cacodylate buffer $(\mathrm{pH} 7 \cdot 2)$ and then fixed in paraformaldehyde-glutaraldehyde fixative buffered with sodium cacodylate/ $\mathrm{HCl}(\mathrm{pH}$ 7·4). ${ }^{21}$ Buttons were postfixed in osmium and dehydrated through a graded series of ethanols. Amyl acetate was used as a transitional solvent. Specimens were then critical-point dried, mounted, and sputter coated with gold. Corneal buttons were coded and prepared for scanning electron microscopy.

Selected specimens were ptepared for light microscopy by vital staining of the corneal endothelium with trypan blue/alizarin red double staining. ${ }^{22}$ Stained buttons were observed under medium power on a standard laboratory Nikon binocular microscope.

\section{Results}

\section{CLINICAL EVALUATION}

At the time of evaluation ( 24 hours post perfusion), all eyes had grossly clear central corneas. There was
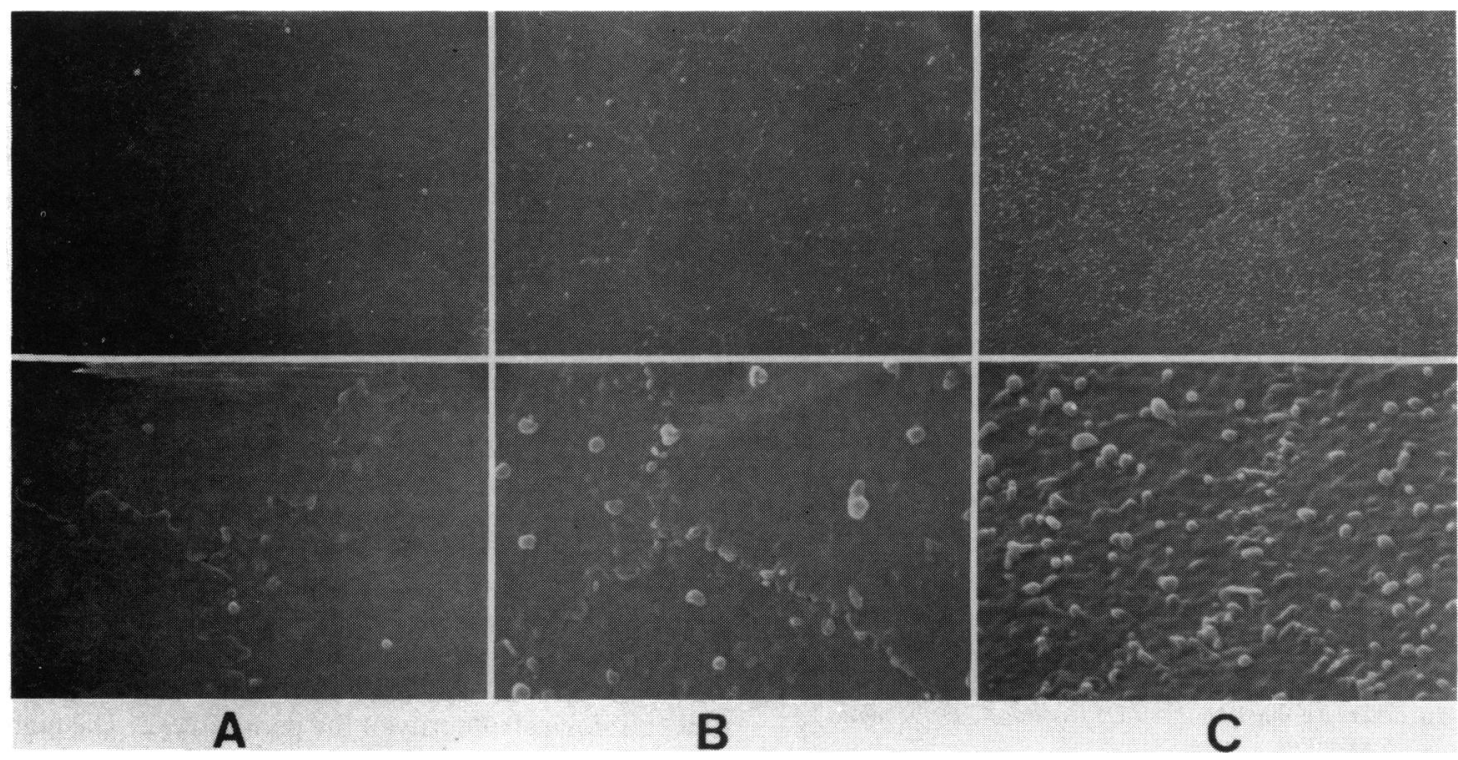

Fig. 1 Three characteristic scanning electron micrographs of cat endothelium scored for (1) the prominence of intercellular interdigitations and (2) the predominance of cell surface projections. A: Score $=0$, flat interdigitations and few cell surface projections. B: Score=1, intermediate. C: Score=2, prominent interdigitations and numerous surface projections. 
no evidence of central corneal oedema. In many of the specimens there was peri-incisional oedema at the limbus; however, in no case did the oedema extend into the central cornea. Anterior chambers were uniformly deep and were without fibrin strands or blood.

\section{FUNCTIONAL EVALUATION (VITAL STAINING)}

Two cats ( 4 eyes: 1 hypothermic, 1 normothermic, 2 corresponding controls) were evaluated by trypan blue/alizarin red vital staining to demonstrate cell viability. Uptake of alizarin red was uniform over the central buttons without focal or regional irregularities. There was no staining by trypan blue in the central button of any of the 4 eyes examined. In peripheral regions damaged by manipulation in removing the corneas the uptake of stain by damaged nuclei was readily apparent.

\section{MORPHOLOGICAL EVALUATION (SCANNING ELECTRON MICROSCOPY)}

The eyes of 11 cats were studied by scanning electron microscopy. Nine cats (18 eyes: 4 hypothermic, 5 normothermic, and 9 corresponding controls) underwent perfusion procedures. Two cats (4 eyes: all unperfused) served as double controls. Scanning electron micrographs of each specimen at $1250 \times$, $2500 \times$, and $10000 \times$ were independently evaluated by 3 observers (E.D., D.H., M.M.) without knowledge of the treatment category. Specimens (masked) were grouped morphologically by 2 criteria: (1) the prominence of intercellular interdigitations and (2) the predominance of cell surface projections.

Each specimen was assigned a score of 0,1 , or 2 for each of these 2 criteria by 3 independent observers

Table 1 Cumulative scores assigned by observers to masked scanning electron micrographs of cat corneal endothelium

\begin{tabular}{|c|c|c|c|}
\hline & Cat & OS (Control) & $O D($ Experimental $)$ \\
\hline \multicolumn{4}{|l|}{$\begin{array}{l}\text { Experimental group I } \\
\text { Hypothermic }\end{array}$} \\
\hline \multirow[t]{5}{*}{ (4 cats- 8 eyes) } & A & 5 & 5 \\
\hline & B & 5 & 3 \\
\hline & & $\overline{\mathrm{x}}=3.5$ & $\overline{\mathbf{x}}=3.75$ \\
\hline & C & 2 & 3 \\
\hline & D & 2 & 4 \\
\hline \multirow{6}{*}{$\begin{array}{l}\text { Experimental group II } \\
\text { Normothermic } \\
\text { (5 cats-10 eyes) }\end{array}$} & & & \\
\hline & $\mathrm{E}$ & 2 & 4 \\
\hline & $\mathrm{F}$ & 10 & 10 \\
\hline & G & $7 \bar{x}=6.8$ & $9 \bar{x}=7 \cdot 4$ \\
\hline & $\mathrm{H}$ & 10 & 10 \\
\hline & I & 5 & 4 \\
\hline \multirow{3}{*}{$\begin{array}{l}\text { Experimental group III } \\
\text { Double control } \\
\text { ( } 2 \text { cats }-4 \text { eyes })\end{array}$} & & OS (control) & $O D$ (control) \\
\hline & $\mathbf{J}$ & 0 & 0 \\
\hline & $\mathbf{K}$ & $5^{\bar{x}=2 \cdot 5}$ & $5^{\bar{x}=2 \cdot 5}$ \\
\hline
\end{tabular}

unaware of the perfusion temperature $(6$ scores of 0 , 1 , or 2 for each specimen). Fig. 1 illustrates the 3 morphological categories. For each specimen the 6 scores obtained were combined and a value of $0-12$ was assigned to each masked specimen with 0 indicating flat intercellular junctions and few surface projections, and 10 (the maximum score obtained) indicating prominent intercellular junctions and numerous surface projections. Table 1 lists the cumulative scores for each specimen, as well as the mean score $(\bar{x})$ for each perfusion group. In no case was there evidence of regional or widespread anatomical abnormalities consistently related to a treatment or control group. A matched pairs $t$ test revealed no significant difference between readings of the left and right eyes. A scatter plot regression analysis $(r=0.89)$ did not rule out a line of identity for right eye vs. left eye. Differences between specimens appeared to be a function of cat variation.

\section{Discussion}

The results of this study suggest that at the scanning electron microscopic level there is no detectable morphological difference hetween endothelial cells perfused under hypothermic conditions and those perfused with ambient temperatures 24 hours post perfusion. In addition vital staining does not suggest a deleterious effect of moderate hypothermia.

For any of the 3 experimental groups the average score of the perfused corneas differed by less than $10 \%$ from fellow control eyes, suggesting that the frequency of raised intercellular junctions and surface projections is unrelated to operative intervention. Individual differences can be explained by cat variation. The apparent difference in scoring between groups I and II is accounted for by a small sample size in which there is a high degree of intercat variation. Clinically we were unable to detect. any signs of gross corneal dysfunction with hypothermic perfusion.

Binder et al. noted endothelial damage with irrigation, even at ambient temperatures. ${ }^{1}$ It should be noted, however, that the flow rate used in that study $(26 \mathrm{ml} / \mathrm{min})$ was over 5 times that used in the present study. We chose $5 \mathrm{ml} / \mathrm{min}$ as the flow rate because this more closely approximates flow rates used in closed pars plana surgery in which there is prolonged perfusion. This reduction in flow rate may account for the absence of endothelial cell damage in the present study. Comparison with the opposite eye as a nonoperative control adds confirmation to the morphological integrity of the perfused eye. The high degree of intercat variation is a bilateral phenomenon and was not altered in this study of unilateral perfusion. 
Other factors must be considered before conclusions can be drawn. If endothelial dysfunction (transient or permanent) is mediated in any fashion by perfusate temperature, all but gross effects may not be detectable by either vital staining or scanning electron microscopy. Other methods of observation more sensitive to functional physiology such as postperfusion ultrasonic pachymetry or endothelial fluorophotometry may be necessary. Secondly, longer perfusion time such as used by Edelhauser $e t$ $a l^{3}$ may prove deleterious under hypothermic conditions. Further, there are recognised difficulties associated with the accuracy of temperature measurements in the eye, including falsely low readings due to conduction loss in exposed thermal probes $^{23}$ and variability induced by environmental factors on the anterior segment resulting in increased error in temperature measurements. ${ }^{24}{ }^{25}$ And finally, as previously mentioned, the small sample size in this study must be considered.

The significant implication of the present findings is that, although moderately hypothermic perfusion does not demonstrate any beneficial effect when compared with normothermic perfusion at similar rates, it also appears to be relatively benign at our level of observation. If moderate hypothermia is found to be useful in vitreoretinal surgery, preliminary indications are that it does not place the corneal endothelium at significant risk.

\section{References}

1 Binder PS, Sternberg H, Wickman MG, Worthen DM. Corneal endothelial damage associated with phakoemulsification. $\mathrm{Am} \mathrm{J}$ Ophthalmol 1976; 82: 48-54.

2 Polack FM, Sugar A. The phacoemulsification procedure. II. Corneal endothelial changes. Invest Ophthalmol Visual Sci 1976; 15: 458-69.

3 Edelhauser HF, Jan Horn DL, Hyndiuk RA, Schultz RO. Intraocular irrigating solution. Arch Ophthalmol 1975; 93: 648-57.

4 Edelhauser HF, Jan Horn, DL, Schultz, RO, Hyndiuk RA. Comparative toxicity of intraocular irrigating solutions on the corneal endothelium. Am J Ophthalmol 1976; 81: 473-81.
5 Green K, Hull DS, Vaughn ED, Malizia AA Jr, Bowman K. Rabbit endothelial response to ophthalmic preservatives. Arch Ophthalmol 1977; 95: 2218-21.

6 Van Horn DL, Edelhauser HF, Prodanovich G, Eiferman R, Pederson HF. Effect of the ophthalmic preservative thimerosal on rabbit and human corneal endothelium. Invest Ophthalmol Visual Sci 1977; 16: 273-80.

7 Swan H. Clinical hypothermia: a lady with a past and some promise for the future. Surgery $1973 ; 73$ : 736-58.

8 Fisk RL, Gelfand ET, Callaghan JC. Hypothermic coronary perfusion for intraoperative cardioplegia. Ann Thorac Surg 1977; 23: 58-61.

9 Engedal $\mathrm{H}$. Cardiac hypothermia evaluated by ultrastructural studies in man. J Thorac Cardiovasc Surg 1978; 75: 548-54.

10 Wilson GS. Clinical experience in renal hypothermia. J Urol 1963; 89: 666-9.

11 Farcon EM, Morales P, Al-Askari S. In vivo hypothermic perfusion during renal surgery. Urology 1974; 3: 414-20.

12 McGill C, Taylor B, Acland R, Flint L. Effects of cooling and intraluminal antiseptics on ischemia in small bowel and colon. Surg Forum 1977; 28: 424-5.

13 Bricolo A, Ore GD, Da Pian R, Faccioli F. Local cooling in spinal cord injury. Surg Neurol 1976; 6: 101-6.

14 May DR, Charles S, Wang C, Bakos J. Ocular hypothermia. I. Anterior chamber perfusion. In preparation.

15 Van Horn DL, Hanna C, Schultz, RO. Corneal cryopreservation. II. Ultrastructural and viability changes. Arch Ophthalmol 1970; 84: 655-67.

16 Van Horn DL. Functional and ultrastructural changes in cryopreserved corneas. Arch Ophthalmol 1973; 90: 312-8.

17 Edelhauser HF. Functional survival of cryopreserved corneal tissue. In: Capella JA, Edelhauser HF, Van Horn DL, eds. Corneal preservation. Springfield: Thomas, 1973: 280-6.

18 Kaufman HE, Capella JA. Preserved corneal tissue for transplantation. J Cryosurg 1968; 1: 125-9.

19 Harris JE, Nordquist LT. The hydration of the cornea. I. The transport of water from the cornea. Am J Ophthalmol 1955; 40: $100-11$.

20 Van Horn DL, Sendele DD, Siedeman S, Buco PJ. Regenerative capacity of the corneal endothelium in rabbit and cat. Invest Ophthalmol Visual Sci 1977; 16: 597-613.

21 Karnovsky MJ. A formaldehyde-glutaraldehyde fixative of high osmolality for use in electron microscopy. J Cell Biol 1956; 27: 127a-138a.

22 Spence DJ, Peyman GA. A new technique for the vital staining of the corneal endothelium. Invest Ophthalmol Visual Sci 1976; 15: 1000-2.

23 Fatt I, Forester JF. Errors in eye tissue temperature measurements when using a metallic probe. Exp Eye Res 1972; 14: 270-6.

24 Rosenbluth RF, Fatt I. Temperature measurements in the eye Exp Eye Res 1977; 25: 325-41.

25 Freeman RD, Fatt I. Environmental influence on ocular temperature. Invest Ophthalmol Visual Sci 1973; 12: 596-602. 